\title{
Practice patterns of respirologists in Canada
}

\author{
Sat Sharma MD FRCPC, Anil Dhar MD FRCPC, Laura McLean MD FRCPC, \\ Perry Sahni MD, Morley Lertzman MD FRCPC
}

\author{
S Sharma, A Dhar, L McLean, P Sahni, M Lertzman. Practice \\ patterns of respirologists in Canada. Can Respir J \\ 2002;9(6):395-400.
}

The demographics and practice patterns of respirologists in Canada have not been studied. To evaluate the demographic characteristics of respirologists in practice, appraise current respirology manpower and ascertain the utilization of invasive diagnostic and therapeutic procedures (interventional pulmonology), a mail survey of all Canadian respirologists was conducted. The questionnaires were completed by $62 \%(n=355)$ of 573 possible participants. Of the respirologists who responded, $69.2 \%$ were younger than 50 years of age, $70.3 \%$ had been in practice for fewer than 20 years, $64.4 \%$ were in full- or part-time academic practice, and $72.9 \%$ were based in urban centres with a catchment population of more than 250,000. The current ratio of respirologists to population in Canada, assuming a total population of $31,000,000$, is $1: 54,101$. In the present survey, only $68.3 \%$ respirologists practised clinical respirology for $50 \%$ or more of their time, and half $(49.5 \%)$ of respirologists devoted more than $50 \%$ of their time on nonrespirology or nonclinical activities. Thus, the more precise respirologist to population ratio appears to be $1: 81,000$. The current ratio meets the Royal College of Physicians and Surgeons of Canada recommendations, and the current training programs meet present manpower requirements. With respect to the procedures performed, most specialists carried out bedside procedures and flexible bronchoscopy; a much smaller number did invasive procedures such as rigid bronchoscopy (20.8\%), transbronchial needle biopsy of lung (43\%), transbronchial biopsy of mediastinal lymph nodes (38\%), therapeutic bronchoscopy using laser, cryotherapy and stents (8.7\%), transthoracic needle biopsy (22.2\%) and thoracoscopy (11.3\%). Because $97 \%$ of pulmonary specialists would like to perform invasive procedures, fellowship programs, mini-residencies and practical courses should provide the necessary training.

Key Words: Interventional pulmonology; Manpower; Practice patterns; Respirologists

\section{Habitudes de pratique des pneumologues au Canada}

RÉSUMÉ : Les caractéristiques démographiques et les modes de pratique des pneumologues au Canada n'ont pas fait l'objet d'études. Pour évaluer les caractéristiques démographiques des pneumologues en pratique active, évaluer la main-d'œuvre actuelle dans ce domaine et vérifier l'utilisation des interventions diagnostiques et thérapeutiques effractives (pneumologie interventionnelle), un questionnaire d'enquête a été posté à tous les pneumologues canadiens. Les questionnaires ont été remplis par $62 \%$ (355) des 573 participants potentiels. Parmi les pneumologues qui ont répondu, $69,2 \%$ avaient moins de 50 ans, 70,3\% étaient en pratique depuis moins de 20 ans, 64,4\% avaient des postes universitaires à temps complet ou à temps partiel et 72,9\% œuvraient en milieu urbain auprès d'une population de plus de 250000 habitants. Au Canada, en supposant une population totale de 31 millions, on estime à 1:54 101 le nombre de pneumologues par habitants. Dans la présente enquête, seulement 68,3 \% des pneumologues pratiquaient en pneumologie clinique plus de $50 \%$ du temps et la moitié (49,5\%) des pneumologues consacraient plus de $50 \%$ de leur temps à des activités non liées à la pneumologie ou à la médecine clini-que. Ainsi, le ratio plus précis semblerait 1:81 000. Le rapport actuel correspond aux recommandations du Collège royal des médecins et chirurgiens du Canada et les programmes de formation en vigueur répondent aux besoins courants en matière de main-d'œuvre. En ce qui a trait aux interventions effectuées, la plupart des spécialistes procédaient à des interventions et à des bronchoscopies au chevet, un nombre beaucoup moindre procédaient à des interventions effractives comme la bronchoscopie rigide (20,8\%), la biopsie à l'aiguille transbronchique (43\%), la biopsie des ganglions lymphatiques médiastinaux transbronchique (37\%), la bronchoscopie thérapeutique au moyen du laser, de la cryothérapie et des tuteurs $(8,7 \%)$, la biopsie transthoracique à l'aiguille (22,2 \%) et la thoracoscopie (11,3\%). Étant donné que $97 \%$ des pneumologues aimeraient effectuer des interventions effractives, des programmes post-universitaires, des mini-résidences et des cours pratiques devraient être préparés à cette fin.

Section of Respirology, Department of Internal Medicine, University of Manitoba, Winnipeg, Manitoba

Correspondence and reprints: Dr Sat Sharma, Program Director, Section of Respirology, University of Manitoba, St Boniface General Hospital, BG034-409 Tache Avenue, Winnipeg, Manitoba R2H 2A6. Telephone 204-237-2217, fax 204-231-1927, e-mail ssharma@sbgh.mb.ca 
$\mathrm{T}$ o determine the future need for respirologists in Canada, it is necessary to collect data on the age, distribution and practice patterns of Canadian respirologists. The American College of Chest Physicians (ACCP) suggests that the ratio of the practicing respirologists to population should optimally be 1:50,000 (1). In Canada, the Royal College of Physicians and Surgeons of Canada (RCPSC) recommends a ratio of 1:81,000 (2). Respiratory specialists often have other clinical (general internal medicine or intensive care medicine) and nonclinical (administration, teaching and research) commitments. How much time Canadian respirologists spend away from clinical respirology is not known. Furthermore, not all practicing respirologists in Canada are listed on the RCPSC specialist register. Although some published data on the practice profile of pulmonary specialists in United States and other countries exist (3-5), no such information for Canadian respirologists is available.

In addition, the practice of respirology has evolved into a procedure-orientated specialty over the past 25 years. Currently, diagnostic flexible bronchoscopy and other invasive procedures have become routine for most respirologists in Canada. These procedures have greatly enhanced the understanding of pulmonary medicine and dramatically improved the ability to diagnose and treat a variety of lung disorders. Interventional respirology is defined as "performance of the diagnostic and therapeutic procedures that are generally performed away from the bedside, require more expertise and involve more risk, eg, bronchoscopy" (6). These procedures include fiberoptic bronchoscopy, rigid bronchoscopy, therapeutic bronchoscopy using laser, electrocautery, cryotherapy or stents, endobronchial irradiation, transbronchial and transthoracic needle aspiration, and medical thoracoscopy for the diagnosis and treatment of pleural diseases. All respirologists may not wish to be able to perform all of the procedures described as 'interventional'; however, all chest physicians should become familiar with the indications, contraindications, and the role that these procedures play in the workup and management of patients with various pulmonary disorders.

The objectives of the present study were to develop an understanding of the practice profile of respirologists and its implications for respirology manpower in Canada. Additionally, the authors sought to learn the clinical application of invasive diagnostic and therapeutic procedures identified as interventional by Canadian respirologists.

\section{DATA AND METHODS}

A questionnaire consisting of 19 questions was created to study the demographic profile and practice patterns of respirologists in Canada. The questionnarire was mailed in August 1999; a second mailing was made four weeks later. Questionnaires were completed anonymously. The questionnaire also sought to obtain information on the specific procedures performed by respirologists, the reasons for not performing the specific procedures, the number of procedures performed yearly, how physicians gained their proficiency to perform the procedures and physicians' views on the impor- tant topic of interventional procedures. The survey was mailed to all physicians listed as respirologists on the RCPSC registry (7). Additionally, Canadian pulmonary medicine specialists listed in ACCP Membership Directory (8) and Canadian Medical Directory (9), but not listed on RCPSC registry, were also included.

\section{RESULTS}

The questionnaire was mailed to 621 respirologists in Canada. Thirty-three questionnaires could not be delivered; 573 respirologists with practice addresses in Canada received the survey. Three hundred fifty-five (62\%) respirologists returned the completed survey. The demographics of the respondents are presented in Table 1. Of all respirologists, a majority $(61.2 \%)$ were between 36 and 50 years of age, and a substantial percentage $(26.3 \%)$ were older than 50 years of age. There were $84.8 \%$ male and $15.2 \%$ female respirologists in Canada. Approximately one-half of all physicians are geographic full-time (full-time academic appointment to Faculty of Medicine) (47.8\%), a significant percentage $(34.7 \%)$ were in full-time private practice, and others (14\%) had part-time academic appointments. A minority $(7.1 \%)$ of respirologists practiced in rural areas where the catchment population was fewer than 100,000 population, and a majority $(52.8 \%)$ practiced in cities whose population is more than 500,000 people.

Information on the practice profile (Table 2) of respirologists indicated that $31.7 \%$ spend less than $50 \%$ of their time practicing respirology and $68.3 \%$ spend more than $50 \%$ of their time in the practice of respirology. A substantial number $(37.9 \%)$ worked in general internal medicine for $10 \%$ to $25 \%$ of their time and a smaller percentage $(17.6 \%)$ worked in general internal medicine for $25 \%$ to $50 \%$ of their time. A fair number $(36.1 \%)$ also practiced critical care medicine for $10 \%$ to $25 \%$ of their time, and $18.8 \%$ spent $25 \%$ to $50 \%$ of their time in critical care. Only a minority of physicians $(7.8 \%)$ mainly specialized in sleep disorders, spending more than $50 \%$ of their time in this area. Most respirologists were predominantly clinicians; $66.8 \%$ did clinical practice for more than $50 \%$ of their time, compared with $33.2 \%$ who spent less than $50 \%$ of their time in clinical practice. Approximately one-half of all physicians (48.8\%) taught for $10 \%$ to $25 \%$ of their time, and $13.6 \%$ had a major teaching commitment, spending between $25 \%$ and $50 \%$ of their time teaching. More than one-half of all physicians participated in research: $45.9 \%$ spent less than $10 \%$ of their time in research, $27.3 \%$ spent $11 \%$ to $25 \%$ of their time in research and $13 \%$ spent $25 \%$ to $50 \%$ of their time in research. A smaller percentage $(13.8 \%)$ were primarily researchers and conducted research for more than $50 \%$ of their time. A significant number of physicians were involved in administration: $31 \%$ spent $10 \%$ to $25 \%$ of their time in administration and $8.1 \%$ spent more than $25 \%$ of their time performing administrative activities.

Most specialists performed bedside procedures; these included thoracentesis (94.3\%), closed needle pleural biop- 
sy $(86.7 \%)$, chest tube placement $(73.2 \%)$, pleurodesis (71.8) and endotracheal intubation (81.4\%).

With respect to interventional procedures (Table 3), fiberoptic bronchoscopy was performed by $87.2 \%$ of physicians and transbronchial forceps biopsy was performed by $80 \%$. A much smaller number of physicians (16\%) performed rigid bronchoscopy. Transbronchial needle aspiration of lung masses or mediastinal lymph nodes is performed by only $43 \%$ of respirologists. A minority (18.2\%) of physicians performed transthoracic needle biopsy and a much smaller number $(5.7 \%)$ conducted therapeutic bronchoscopy with endobronchial laser, stent placement, cryotherapy or brachytherapy. Only $8 \%$ were proficient in medical thoracoscopy.

Regarding the number of procedures performed in a year, most respirologists performed more than 25 flexible bronchoscopies, 11 to 25 rigid bronchoscopies and 11 to 25 transbronchial forceps biopsies. Of those who performed transbronchial needle aspiration of lung masses or mediastinum lymph nodes, they performed 10 to 25 procedures in a year. Transthoracic needle biopsy, therapeutic bronchoscopy using laser, stent placement, cryotherapy and brachytherapy, and medical thoracoscopy (for diagnosis and therapy of pleural disorders) were performed fewer than 10 times per year.

When asked why respirologists do not perform the invasive procedures, $48 \%$ of the respondents indicated that they did not have the necessary training, 10.3\% indicated that they did not have the equipment available and $16.5 \%$ indicated that they were not interested. When asked whether respirologists should perform invasive diagnostic and therapeutic procedures, $97 \%$ said that they should. Most physicians worked in facilities in which a thoracic surgeon also performed these procedures (83\%). When asked which of the interventional procedures respirologists should perform, most physicians suggested flexible bronchoscopy (96\%), transbronchial forceps biopsy (87\%) and transbronchial needle aspiration biopsy of the lung or mediastinum lymph nodes (81\%). Only 36\% indicated
TABLE 1

Demographics of respirologists in Canada

\begin{tabular}{lc}
\hline Characteristic & Percentage of total \\
\hline Age (years) & 8.2 \\
$<35$ & 61.2 \\
36 to 50 & 26.3 \\
51 to 65 & 4.3 \\
$\quad>65$ & \\
Sex & 84.8 \\
$\quad$ Male & 15.2 \\
Female & \\
Years in practice & 35.7 \\
1 to 10 & 34.9 \\
11 to 20 & 22.6 \\
21 to 30 & 5.1 \\
31 to 40 & 1.7 \\
41 to 50 & \\
Type of practice & 47.8 \\
Academic full-time & 14 \\
Academic part-time & 34.7 \\
Private practice & \\
Catchment area of practice & 7.1 \\
$<100,000$ people & 18.2 \\
100,000 to 250,000 people & 22 \\
250,000 to 500,000 people & 52.8 \\
$>500,000$ people & \\
\hline
\end{tabular}

that rigid bronchoscopy should be performed by pulmonologists; $49 \%$ indicated that transthoracic needle biopsy should be performed by respirologists, and $41 \%$ indicated that therapeutic bronchoscopy using laser, stent placement or brachytherapy should be performed by respirologists. Only 35\% indicated that respirologists should be proficient in medical thoracoscopy.

TABLE 2

Practice profile of Canadian respirologists

\begin{tabular}{|c|c|c|c|c|c|}
\hline & \multicolumn{5}{|c|}{ Time spent in other disciplines (\%) } \\
\hline & $<10 \%$ & $11 \%$ to $25 \%$ & $26 \%$ to $50 \%$ & $51 \%$ to $75 \%$ & $>75 \%$ \\
\hline Respirology & 1.7 & 11 & 19 & 23.5 & 44.8 \\
\hline General internal medicine & 41.7 & 37.9 & 17.6 & 2.7 & 0 \\
\hline Critical care & 36.1 & 36.1 & 18.8 & 4.2 & 4.7 \\
\hline \multirow[t]{3}{*}{ Sleep disorders } & 57 & 26.6 & 8.5 & 5.6 & 2.2 \\
\hline & \multicolumn{5}{|c|}{ Time spent in various activities (\%) } \\
\hline & $<10 \%$ & $11 \%$ to $25 \%$ & $26 \%$ to $50 \%$ & $51 \%$ to $75 \%$ & $>75 \%$ \\
\hline Clinical practice & 2 & 10.3 & 20.9 & 28.7 & 38.1 \\
\hline Teaching & 36.6 & 48.8 & 13.6 & 1 & 0 \\
\hline Research & 45.9 & 27.3 & 13 & 12.3 & 1.5 \\
\hline Administration & 60.9 & 31 & 4 & 3.4 & 0.7 \\
\hline
\end{tabular}


TABLE 3

Interventional procedures performed by Canadian respirologists

\begin{tabular}{|c|c|c|c|c|c|c|}
\hline \multirow[b]{2}{*}{ Procedure } & \multirow{2}{*}{$\begin{array}{l}\text { Percentage of } \\
\text { physicians who } \\
\text { perform procedures }\end{array}$} & \multicolumn{5}{|c|}{ Number of procedures per year performed (\%) } \\
\hline & & $<10$ & 11 to 25 & 26 to 50 & 51 to 75 & $>75$ \\
\hline Flexible bronchoscopy & 87.2 & & 8.5 & 19.8 & 16 & 42.9 \\
\hline Rigid bronchoscopy & 16 & & 12.2 & 1.3 & 2.5 & 0 \\
\hline Transbronchial forceps biopsy & 80 & 32.2 & 30.1 & 17.7 & & \\
\hline $\begin{array}{l}\text { Transbronchial needle } \\
\text { aspiration }\end{array}$ & 43 & 24.3 & 12.8 & 5.9 & & \\
\hline Transthoracic needle biopsy & 18.2 & 11.2 & 3.8 & 3.2 & & \\
\hline $\begin{array}{l}\text { Laser/stent/cryotherapy/ } \\
\text { brachytherapy }\end{array}$ & 5.7 & 3.6 & 1.8 & 0.3 & & \\
\hline Medical thoracoscopy & 8 & 3.9 & 2.4 & 1.8 & & \\
\hline
\end{tabular}

Regarding training for conducting invasive procedures, a majority $(48.8 \%)$ indicated that training should be provided for interventional procedures during fellowships; however, $19.9 \%$ stated that mini-residencies and $44.8 \%$ said that practical hands-on courses may offer valuable training.

\section{DISCUSSION}

\section{Practice profile of Canadian respirologists}

The results of the present mail survey provide the only information on the practice profile of Canadian respirologists. These data may be useful in the evaluation of specialist manpower planning in Canada. This information may also be helpful to postgraduate training programs at universities, indicating that fellowship programs include training in interventional procedures. In Canada, most practicing pulmonary specialists are relatively young (younger than 50 years of age), are in full- or part-time academic practice and are based in larger centres. However, because a significant proportion of respirologists are older than 50 years of age and these physicians will likely retire over the next one or two decades, careful manpower planning is required. Furthermore, this study highlights that a minority of physicians, only $7 \%$, practice in smaller centres, perhaps indicating a manpower imbalance. The Ontario Medical Association has recently developed a 'rurality index' to assess access to specialty care in rural Ontario (10). By quantifying several factors, which include travel times to the nearest advanced referral centre, population density and weather factors, the results of this index show that there is poor access to the specialty medical care in rural areas (10).

\section{Respirology manpower issues}

The present study provides a basis for manpower projections, which have implications for all training programs in Canada. The exact number of respirologists in Canada is not known. At the time of survey, there were 361 physicians listed as fellows in good standing with the RCPSC (7). However, we identified additional 212 physicians who were listed in the ACCP Membership Directory and the Canadian Medical Directory $(8,9)$. This substantial number of physicians consists of respirologists who completed their training before the subspecialty examination in respirology came into existence, as well as those trained in the United States, United Kingdom and South Africa, or physicians who chose not to maintain RCPSC Membership and would not be on the RCPSC register. The 1988 recommendations from the RCPSC refer to a ratio of respirologists to population of 1:81,000 (2). Whether this ratio recommends a total number of respirologists or only full-time equivalent clinical respirologists is not known. Furthermore, the recommendation preceded an explosion of sleep disorder centres and intensive care units; both of these are predominantly staffed by respirologists.

The current ratio of respirologists in Canada, assuming a total population of $31,000,000$, is $1: 54,101$, which meets ACCP standards and exceeds RCPSC manpower recommendations (2,11). In our survey, only $68.3 \%$ respirologists practiced clinical respirology for $50 \%$ or more of their time, and $48.3 \%$ and $11.6 \%$ attended on general internal medicine and critical care medicine for more than $25 \%$ and $50 \%$ of their time, respectively. Furthermore, one-half (49.5\%) of respirologists spent more than $25 \%$ of their time on nonclinical activities such as teaching, research and administration. These results are similar to a previous RCPSC workforce study (11) and significantly overestimate the number of full-time equivalent clinical respirologists. Because one-half of respirologists devote more than $50 \%$ of their time to activities other than clinical respirology, a more exact respirologist to population ratio is $1: 81,000$. Therefore, Canada would require 574 physicians with a practice profile similar to the one uncovered by this survey. Current manpower may be adequate according to the RCPSC recommendations, in which the respirologists were expected to allocate some of their time to academic and other professional activities (2).

Currently, there are $26.3 \%$ of respirologists in the age group of 51 to 65 years and $4.3 \%$ are older than 65 years. Approximately, 30\% may retire over the next 10 to 15 
years. We are currently training 16 to 20 respirologists per year; the retention rate for these RCPSC trainees is approximately $75 \%$, indicating that 12 to 14 set up practice in Canada. Consequently, contemporary supply appears to be sufficient to replace retiring physicians and to maintain a stable level of respirology manpower in Canada. However, with an aging population and population growth, we may need more respirologists than we currently train. The Committee on Manpower for Pulmonary and Critical Care Societies conducted an estimate of current and future requirements for adult critical care and pulmonary medicine physicians in the United States (12). This report projected a shortfall of pulmonary physicians beginning in 2007, and forecast a deficit of $35 \%$ by 2020 and $46 \%$ by 2030. A similar situation is expected to occur in Canada; consequently, the future health care needs of an aging Canadian population may outpace the future supply of respirologists.

Our data differ from the report on respirology manpower in Canada by Cockroft et al (13); these authors indicated that only 361 respirologists practice in Canada. This is a gross underestimation of the number of Canadian respirologists, because the RCPSC registry is incomplete. For example, Cockroft listed seven respirologists in Manitoba in the year 2000, but there were eight additional respirologists in Manitoba that year who were not on the RCPSC register. In the present study, we identified 573 respirologists in Canada. Pediatric respirologists were included in this survey; however, we excluded all Canadian respirologists residing outside of the country.

Another way to assess whether there is a sufficient number of physicians is by quantifying the waiting times for referrals. However, this depends heavily on factors other than manpower, such as the availability of local resources (sleep laboratory beds), operating room time for bronchoscopies and ambulatory care clinic time. Advertisements for respirology positions across the country may be another way to assess ongoing manpower demand; there appears to be a few such notices in Canadian journals.

\section{Interventional pulmonology}

Commonly performed bedside procedures are an essential part of the practice of respirology and are performed by a considerable number of physicians who receive training for these procedures during their residency or fellowship. Whether the performance of more complicated invasive procedures by pulmonologists provides efficient and cost effective care has not been studied.

Fiberoptic bronchoscopy and transbronchial forceps biopsy are performed by most of the practicing respirologists surveyed. Because the majority were younger than 50 years of age, these physicians likely received training during their fellowship programs. A significant percentage of specialists never learned the procedure and would likely refer patients to other respirologists or thoracic surgeons. Most respirologists who performed the invasive procedures completed more than 50 flexible fiberoptic bronchoscopies per year and over 10 transbronchial biopsies per year. These perhaps should be the minimum number required by the hospitals and provincial colleges to maintain competence.

A minority of respirologists in Canada performs the newer invasive procedures such as transbronchial needle biopsy, rigid bronchoscopy, stent placement and medical thoracoscopy, despite that these procedures have moved into mainstream respirology over the past 10 to 15 years. Transbronchial needle biopsy of the lung and the mediastinal lymph nodes is widely performed by pulmonologists in the United States, but fewer than 50\% of Canadian physicians are proficient in this procedure. Transthoracic needle biopsy has been taken over primarily by radiologists in many centres, but a surprising $22 \%$ of respirologists report performing this procedure. Endoscopic interventional procedures, including laser bronchoscopy, cryotherapy and the placements of stents, are performed by a much smaller number of specialists. Medical thoracoscopy is primarily indicated for the diagnosis and treatment of pleural disorders; this procedure is performed by $11 \%$ of all respirologists.

Our data indicate that Canadian pulmonary physicians were more likely to perform bedside or interventional procedures if they were trained formally during fellowship programs. A substantial number of physicians sought proficiency by attending mini-residencies and special instructional courses. Such continuing medical education courses should be encouraged to teach newer technology to practicing physicians and to help maintain their skills.

Finally, we explored the views of the practicing respirology community about whether these newer procedures should be widely adopted. A majority of respondents (97\%) indicated that respirologists should not only perform fiberoptic bronchoscopy, but that the specialty should develop expertise in the performance of other newer invasive procedures. On exploring the reasons for not performing these procedures, the respirologists who did not perform invasive procedures were asked to provide a reason why. No uniform explanation emerged for this question; a number of respirologists suggested that either lack of expertise or the presence of another expert (surgeon or radiologist) in their institution was the possible reason.

\section{SUMMARY}

Data on the demographics and practice patterns of respirologists in Canada have been collected. Our data also provide an estimate of the number of respirologists that will be required in Canada in the future. There is a perception that a large shortfall of respirology manpower exists in Canada. The results of this survey suggest that, although there may now be an adequate number of respirologists in Canada, in future, a deficit of respirologists may occur unless the training programs keep pace with the increased demand that is likely to occur with the aging population. Our study also provides important data on the performance of interventional procedures, which have become an integral part of 
practice of respirology in Canada. While a growing number of physicians have developed expertise with and practice these procedures, several other newer techniques have not been widely adopted. The respirology community in Canada proposed that these procedures should become part of the mainstream respirology; accordingly, fellowship programs and continuing education programs, in the form of mini-residencies and practical hands-on courses, should offer the requisite training.

\section{REFERENCES}

1. Pulmonary disease manpower survey. Report of the Joint Committee, American Thoracic Society, American College of Chest Physicians. Chest 1973;63:790-2.

2. Low JA. National Specialty Physician Review. Ottawa: Royal College of Physicians and Surgeons of Canada, 1988.

3. Prakash UBS, Offord KP, Stubbs SE. Bronchoscopy in North America: the ACCP Survey. Chest 1991;100:1668-75.

4. Honeybourne D, Neumann CS. An audit of bronchoscopy practice in the United Kingdom: a survey of adherence to national guidelines. Thorax 1997;52:709-13.
5. Antic R, Crockett A, Field G, Finucane KE, Smith M. Guidelines for Training and Competency of Bronchospies Using Flexible Fiberoptic Instruments. Sydney: Thoracic Society of Australia, 1986.

6. Mathur PN, Beamis JF. Interventional pulmonology. Clin Chest Med 1995;16:xi-xii.

7. The Royal College of Physicians and Surgeons of Canada. Analysis of Specialty and Subspecialty Certification of Fellows in Good Standing, June 11, 1999. Ottawa: Royal College of Physicians and Surgeons of Canada, 2000

8. American College of Physicians Membership Directory. Northbrook: American College of Physicians, 1999.

9. Canadian Medical Directory. Don Mills: Southam Information Products Group, 1999.

10. Kralj B. Measuring "rurality" for purposes of health-care planning: an empirical measure for Ontario. Ont Med Rev 2000;67:33-52.

11. Scully HE. 1995 RCPSC Specialty Physician Workforce Study. Ottawa: Royal College of Physicians and Surgeons of Canada, 1995.

12. Angus DC, Kelley MA, Schmitz RJ, et al. Committee on Manpower for Pulmonary and Critical Care Societies: Current and projected workforce requirements for care of the critically ill and patients with pulmonary disease; can we meet requirements of an aging population? JAMA 2000;284:2762-70

13. Cockroft DW, Wensley D. Respiratory manpower in Canada A report for the Canadian Thoracic Society Education Committee. Can Respir J 2000;7:451-5 


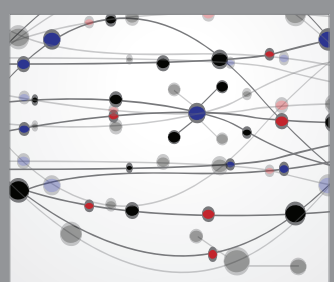

The Scientific World Journal
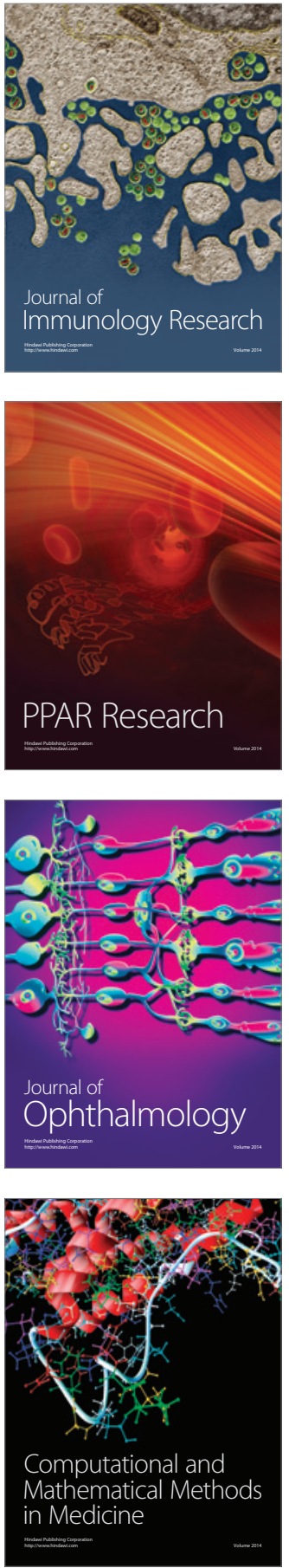

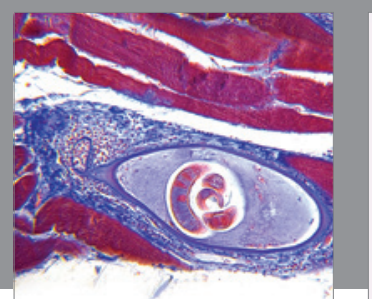

Gastroenterology Research and Practice

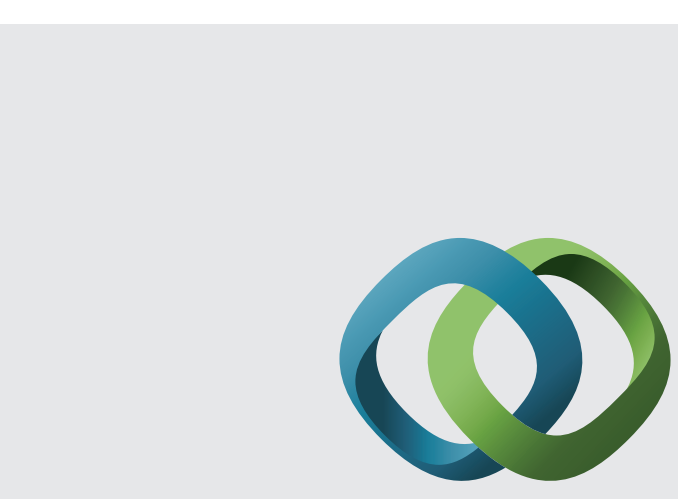

\section{Hindawi}

Submit your manuscripts at

http://www.hindawi.com
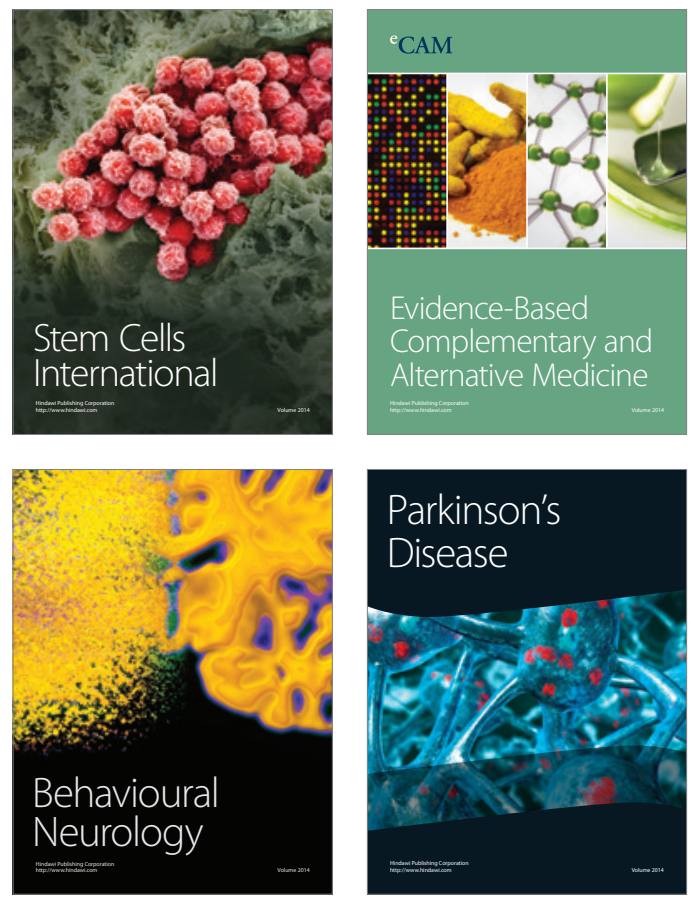
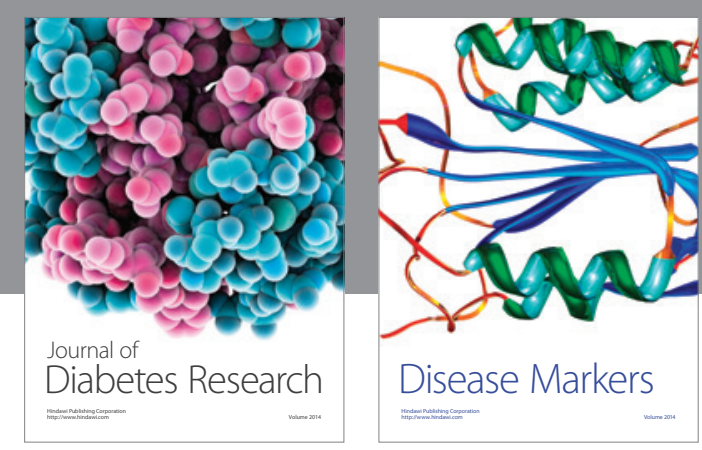

Disease Markers
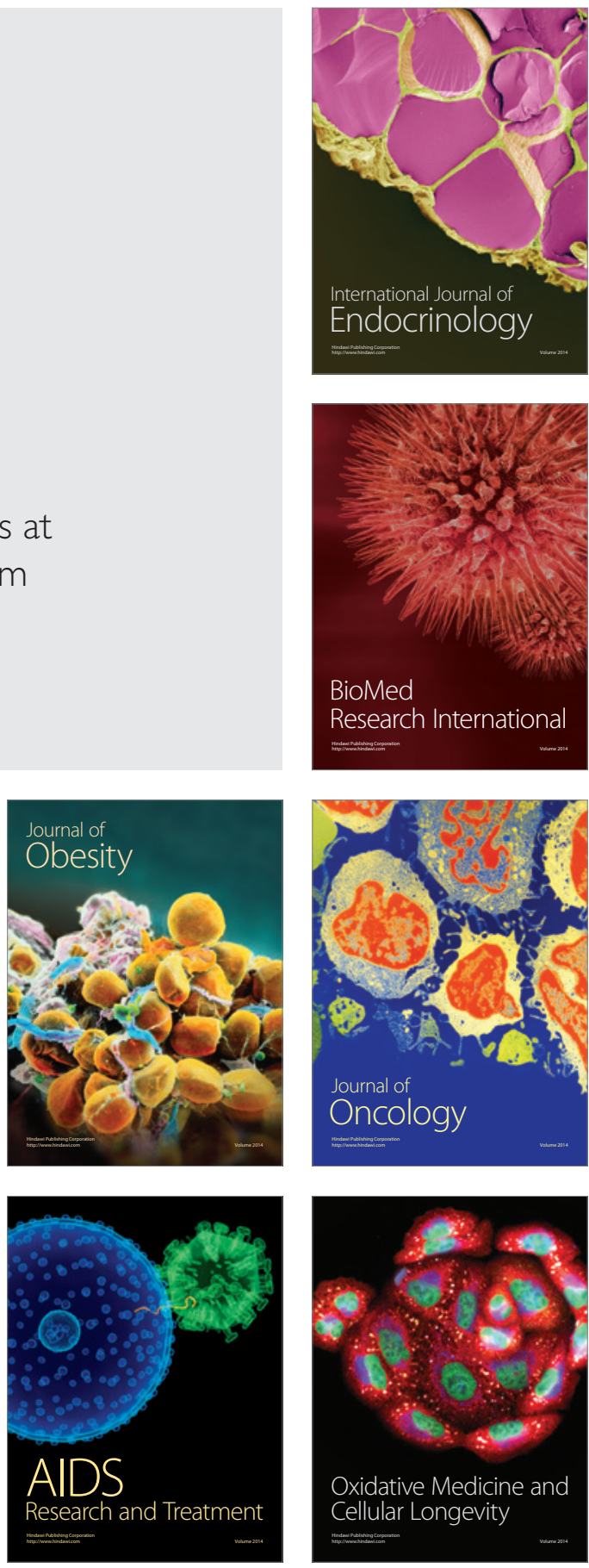